\title{
Necessity of a tourniquet during cemented total knee replacement; let the debate continue
}

\section{Introduction}

The use of the pneumatic tourniquet in limb surgery was introduced by Sir Harvey Cushing in 1904. With the advent of this easier way of tourniquet application, its benefits and use were quickly popularized. Today the pneumatic tourniquet is widely used, particularly in orthopaedic surgery of the limbs inclusive of arthroplasties. Despite several randomized clinical trials the debate of the necessity of a tourniquet in total knee arthroplasty (TKA) continues and its use remains controversial. The vast majority of total knee arthroplasties in the United States are however performed using a tourniquet.

The global prevalence of osteoarthritis of the knee is $3.8 \%$ and is expected to increase with the increasing life expectancy. ${ }^{2}$ This, together with osteoarthritis of the hip, is ranked $11^{\text {th }}$ in contribution to global disability. ${ }^{2}$ Total knee arthroplasty offers a solution to improving the quality of life in these patients. ${ }^{3}$ There however remain unanswered questions with regard to several aspects of the technical details of this procedure, inclusive of the necessity of a tourniquet. ${ }^{4-6}$ The use of a tourniquet during total knee replacement (TKR) offers several benefits but also carries with it certain proven and theoretical risks. Several questions concerning tourniquet use are still up for debate inclusive of cuff pressure, timing of release, timing of inflation, impact on blood loss and tourniquet time above which complications increase.

Theoretically one of the main benefits of using a tourniquet in total knee replacement (TKR) is to facilitate a better bone-cement-implant interface, that is, cementation. This should translate to a longer implant survival, however, data regarding this is lacking. Additionally the use of a tourniquet decreases intraoperative blood loss and allows for better visualization and decreases operative time. ${ }^{7-9}$

The timing of inflation of the tourniquet, whether at the beginning of the procedure or at the time of cementation remains unanswered as well as the timing of release whether it should be done before or after wound closure. The release of the tourniquet prior to wound closure has been shown to increase intraoperative blood loss in randomized clinical trials. ${ }^{8,10}$ A meta-analysis by Rama et al also showed that early release prior to wound closure increased the intraoperative blood loss but also decreased the postoperative complication rate. ${ }^{11}$ The release of a tourniquet allows early identification of major vascular injury. The incidence of this is however very low at $0.17 \% .{ }^{12}$ On the other hand unrecognized injuries have very poor outcomes inclusive of amputations. $^{12}$

There are several potential risks and possible adverse outcomes with the use of a tourniquet. These risks may be neuromuscular, vascular and cutaneous and include wound complications, post operative pain, possible increased risk of symptomatic deep venous thrombosis and knee stiffness.

Neuromuscular events remain the most common adverse outcome, particularly nerve paralysis. It may arise due to ischemia or due to direct pressure and the complication rate increases with total tourniquet time. ${ }^{13-15}$ Postoperative pain is also thought to increase with tourniquet use and may affect rehabilitation, particularly knee flexion. ${ }^{16}$

\author{
Volume 10 Issue 3 - 2018 \\ Daine Clarke \\ Kingston Public Hospital, Jamaica
}

Correspondence: Daine Clarke, Kingston Public Hospital, North Street, Tel 8763228506,Email daineoclarke@gmail.com

Received: October 27, 2017 | Published: June 06, 2018

Application of a tourniquet to the lower limb during TKR has several physiological effects on the cardiovascular system. The majority of these cases are performed for symptomatic relief of osteoarthritis in an aged population with comorbidities of the cardiovascular system. Exsanguination of the lower limbs results in an increase in circulating blood volume by $15-20 \% .{ }^{17}$ This increased circulating blood volume in a diminished vascular tree results in a rise in the total peripheral resistance and increased work for a potentially compromised myocardium.

Release of the tourniquet results in increased vascular return and a $10 \%$ increase in limb size as a result of a reactive hyperaemia. ${ }^{18}$ The reactive hyperaemia is also accompanied by a transient increase in fibrinolysis. This translates to increase haemorrhage post release in the absence of adequate haemostasis. Rama et al suggested that maintaining the tourniquet until wound closure is achieved and adding a compressive bandage results in a tamponade effect until this transient period has passed. ${ }^{11}$

Further controversy exists with the risk of deep venous thrombosis in patients who undergo TKR with the assistance of a tourniquet. Fukuda et al and Wakankar et al both reported no increase in DVT in their study. ${ }^{7,19}$ On the other hand Abdel Salaam and Eyres reported an increase. ${ }^{4}$ For a comparison of the groups and outcome several confounders would have to be eliminated or matched inclusive of the ethnicity of the population at hand.

As it regards blood loss, there have been conflicting reports. ${ }^{20}$ Several studies have reported no difference in total blood loss with or without the use of a tourniquet. ${ }^{20}$ Others have reported increased blood loss without a tourniquet. ${ }^{7,9}$ There is however diversity in reporting of blood loss, while some authors have focused on calculated intraoperative blood loss others have looked at total blood loss i.e fall in haematocrit post operatively. The surgical practices as well have not been standardized and confounders exist chief amongst which is the use of drains. Li et al in their meta- analysis of fifteen studies with a total of 804 patients studies found no difference in the total blood loss with or without the use of a tourniquet. ${ }^{20}$

Currently there are no guidelines nor evidence based recommendation for the use of a tourniquet in total knee arthroplasty. Surgical practices therefore continue to vary without standardization and are mostly based on level four evidence. 


\section{Conclusion}

The debate regarding the use of a tourniquet in cemented total knee arthroplasty remains unsettled. Each case should be individually assessed regarding the potential benefits and risks with tourniquet use and a decision made accordingly.

\section{Acknowledgements}

None.

\section{Conflict of interest}

Author declares there are no conflicts in publishing the article.

\section{References}

1. Berry DJ, Bozic KJ. Current practice patterns in primary hip and knee arthroplasty among members of the American Association of Hip and Knee Surgeons. J Arthroplasty. 2010;25(6 Suppl):2-4.

2. Cross M, Smith E, Hoy D, Nolte S, Ackerman I, Fransen M, et al. The global burden of hip and knee osteoarthritis: estimates from the global burden of disease 2010 study. Ann Rheum Dis. 2014;73(7):1323-30.

3. Rampersaud YR, Wai EK, Fisher CG, Yee AJ, Dvorak MF, Finkelstein JA, et al. Postoperative improvement in health-related quality of life: a national comparison of surgical treatment for focal (one- to twolevel) lumbar spinal stenosis compared with total joint arthroplasty for osteoarthritis. Spine J. 2011;11(11):1033-41.

4. Abdel-Salam A, Eyres KS. Effects of tourniquet during total knee arthroplasty. A prospective randomised study. J Bone Joint Surg Br. $1995 ; 77(2): 250-3$

5. Iorio R, Healy WL. Tourniquet use during total knee arthroplasty did not reduce total blood loss. J Bone Joint Surg Br. 2001;83(8):1282.

6. Jarolem KL, Scott DF, Jaffe WL, Stein KS, Jaffe FF, Atik T. A comparison of blood loss and transfusion requirements in total knee arthroplasty with and without arterial tourniquet. American journal of orthopedics (Belle Mead, NJ). 1995;24(12):906-9.

7. Fukuda A, Hasegawa M, Kato K, et al. Effect of tourniquet application on deep vein thrombosis after total knee arthroplasty. Arch Orthop Trauma Surg. 2007;127(8):671-5.

8. Harvey EJ, Leclerc J, Brooks CE, Burke DL. Effect of tourniquet use on blood loss and incidence of deep vein thrombosis in total knee arthroplasty. The Journal of arthroplasty. 1997;12(3):291-6.
9. Tai TW, Chang CW, Lai KA, et al. Effects of tourniquet use on blood loss and soft-tissue damage in total knee arthroplasty: a randomized controlled trial. J Bone Joint Surg Am. 2012;94(24):2209-15.

10. Ishii Y, Matsuda Y. Effect of the timing of tourniquet release on perioperative blood loss associated with cementless total knee arthroplasty: a prospective randomized study. The Journal of arthroplasty. 2005;20(8):977-83

11. Rama KR, Apsingi S, Poovali S, Jetti A. Timing of tourniquet release in knee arthroplasty. Meta-analysis of randomized, controlled trials. J Bone Joint Surg Am. 2007;89(4):699-705.

12. Calligaro KD, Dougherty MJ, Ryan S, et al. Acute arterial complications associated with total hip and knee arthroplasty. $J$ Vasc Surg. 2003;38(6):1170-7.

13. Shaw JA, Murray DG. The relationship between tourniquet pressure and underlying soft-tissue pressure in the thigh. J Bone Joint Surg Am. 1982;64(8):1148-52.

14. Sapega AA, Heppenstall RB, Chance B, et al. Optimizing tourniquet application and release times in extremity surgery. A biochemical and ultrastructural study. J Bone Joint Surg Am. 1985;67(2):303-14.

15. Horlocker TT, Hebl JR, Gali B, et al. Anesthetic, patient, and surgical risk factors for neurologic complications after prolonged total tourniquet time during total knee arthroplasty. Anesth Analg. 2006;102(3):950-5.

16. Worland RL, Arredondo J, Angles F, et al. Thigh pain following tourniquet application in simultaneous bilateral total knee replacement arthroplasty. The Journal of arthroplasty. 1997;12(8):848-52.

17. Klenerman L, Crawley J. Limb blood flow in the presence of a tourniquet. Acta Orthop Scand. 1977;48(3):291-5.

18. Silver R, de la Garza J, Rang M, et al. Limb swelling after release of a tourniquet. Clin Orthop Relat Res. 1986(206):86-9.

19. Wakankar HM, Nicholl JE, Koka R, et al. The tourniquet in total knee arthroplasty. A prospective, randomised study. $J$ bone joint surg $\mathrm{Br}$. 1999;81(1):30-3.

20. Li X, Yin L, Chen ZY, Zhu L, et al. The effect of tourniquet use in total knee arthroplasty: grading the evidence through an updated metaanalysis of randomized, controlled trials. Eur J Orthop Surg Traumatol. 2014;24(6):973-86. 